\title{
O Modernismo é a cidade: interpretando a leitura dos moradores sobre o patrimônio arquitetônico de Cataguases - MG
}

\begin{abstract}
Modernism is the city: interpreting the residentes 'reading on the architectural patrimony of Cataguases - MG El Modernismo es la ciudad: interpretación de la lectura de los residentes sobre el patrimônio arquitectónico de Cataguases - MG
\end{abstract}

Elias Sampaio

Universidade Federal de Juiz de Fora (UFJF), Brasil

elias.sadres@gmail.com
DOI: https://doi.org/10.18472/cvt.21n1.2021.1871 Redalyc: http://www.redalyc.org/articulo.oa? $\mathrm{id}=115466307005$

Recepción: 13 Octubre 2020

Aprobación: 23 Marzo 2021

\section{Resumo:}

A pesquisa objetiva identificar a relação dos moradores com o patrimônio arquitetônico modernista de Cataguases, fundamentando-se em um roteiro dissertativo de entrevista, aplicado a trinta residentes ao longo do centro urbano. A interpretação dos dados seguiu o método Análise de Conteúdo. Os resultados obtidos revelam que os símbolos culturais de Cataguases representam orgulho para seus moradores, mas sua história ainda é pouco compreendida; denotam o potencial turístico da cidade e o desejo de inserção do turismo na economia local; e possibilita reflexões referentes ao planejamento de um plano interpretativo do patrimônio em conjunto com a comunidade como uma alternativa para resgatar a trajetória do Modernismo na cidade.

Palavras-chave: Cataguases, Patrimônios Culturais, Modernismo, Turismo.

\section{Abstract:}

The research aims to identify the relationship of residents with the modernist architectural heritage of Cataguases, based on an essay, applied to thirty residents throughout the urban center. The data interpretation followed the Content Analysis method. The results obtained reveal that the cultural symbols of Cataguases represent pride for its residents, but its history is still poorly understood; denote the tourist potential of the city and the desire to insert tourism into the local economy; and allows reflections regarding the planning of an interpretative plan of heritage together with the community as an alternative to rescue the trajectory of Modernism in the city.

KEYWORDS: Cataguases, Cultural Heritage, Modernism, Tourism.

\section{Resumen:}

La investigación tiene como objetivo identificar la relación de los vecinos con el patrimonio arquitectónico modernista de Cataguases, a partir de un guión de entrevista de tesis, aplicado a una treintena de vecinos de todo el casco urbano. La interpretación de los datos siguió el método de Análisis de Contenido. Los resultados obtenidos revelan que los símbolos culturales de Cataguases representan un orgullo para sus habitantes, pero su historia aún es poco conocida; denotar el potencial turístico de la ciudad y el deseo de insertar el turismo en la economía local; y permite reflexiones sobre la planificación de un plan interpretativo del patrimonio junto con la comunidad como alternativa para rescatar la trayectoria del Modernismo en la ciudad.

Palabras Clave: Cataguases, Patrimonio Cultural, Modernismo, Turismo.

\section{INTRODUÇÃo}

O Modernismo brasileiro surgiu a partir da necessidade dos artistas expressarem a realidade popular, sem o romantismo ou academicismo presente nas obras artísticas até então. Dois momentos importantes marcaram o início das rupturas com a tradição artística acadêmica vigente: a exposição Expressionista de Anita Malfatti em 1917, considerada como o marco inicial do movimento por alguns historiadores e a Semana de Arte Moderna de 1922 com a popularização dos conceitos e da estética modernista. Assim, o movimento se compôs como uma entidade heterogênea, harmonizando e combinando elementos diversos. Os limiares da 
modernidade artística nacional residiam sobretudo na questão da brasilidade, que praticamente instituiu aos artistas aquilo que a modernidade europeia renegava desde Manet - "[...] o primado do tema, a sujeição da pintura ao assunto" (Fabris, 1994, p. 15).

O Modernismo era repleto de questionamentos políticos e de metáforas sociais. Através das revistas literárias, das artes visuais e da música, os artistas expressavam situações conflituosas que a arte acadêmica em vários momentos renegou. Nas artes visuais houve um engajamento social em proximidade à esquerda, como pode ser percebido nas obras de Portinari. A primeira fase do movimento orientou-se no sentido da renovação e do nacionalismo. Já no segundo momento, em meados da década de 1930, a questão social ganhou força representativa. De modo geral, a dinâmica modernista se empenhou na "conscientização", se preocupando em ser uma arte popular, sendo o povo o seu tema e espectador ideais (Zilio, 1994).

O presente artigo disserta majoritariamente sobre as manifestações modernistas em Cataguases (estado de Minas Gerais - MG) na arquitetura e nos painéis pictóricos de azulejo, construídos no decorrer das décadas de 1940 a 1960, tendo como principais expoentes Oscar Niemeyer na arquitetura e Candido Portinari na pintura. Localizada a $320 \mathrm{~km}$ da capital Belo Horizonte, a cidade ocupa um território de $431,767 \mathrm{~km}^{2}$, com aproximadamente 74.000 habitantes e de economia predominantemente industrial. Segundo Alonso (2012), o desenvolvimento cultural da cidade se deu através das relações socioeconômicas mantidas com o Rio de Janeiro durante a transição entre os séculos XIX e XX. A ferrovia e a formação de uma elite intelectual foram elementos decisivos para o crescimento de um cenário favorável às artes e à cultura, particularmente ao movimento modernista.

Cataguases é popularmente caracterizada como uma "galeria a céu aberto", pois reúne onze edificações modernistas tombadas pelo Instituto do Patrimônio Histórico e Artístico Nacional (IPHAN) em 1994. Destarte, essas construções constituem o patrimônio cultural de Cataguases. O Artigo 2016 da Constituição de 1988 “[...] conceitua patrimônio cultural como sendo os bens 'de natureza material e imaterial, tomados individualmente ou em conjunto, portadores de referência à identidade, à ação, à memória dos diferentes grupos formadores da sociedade brasileira [...]” (IPHAN, 2014, s/p).

Uma situação ocorrida na cidade nos faz questionar sobre a valorização do patrimônio cultural local por parte da população. Nesta ocasião, os comerciantes não aceitaram facilmente o decreto municipal 4.360/2015, que estabelece diretrizes para a instalação de anúncios publicitários nas fachadas dos estabelecimentos no sítio histórico tombado. A prefeitura argumentou que a utilização dos letreiros, muitas vezes de forma errônea, ocasiona poluição visual e invisibiliza as edificações históricas. Desta forma, a administração municipal precisou adotar medidas para o comprimento das diretrizes estabelecidas, sendo aplicado multas ou interdição em estabelecimentos que descumprissem o decreto.

Tendo como objeto central deste estudo o patrimônio modernista, questiona-se: qual a percepção do morador sobre os símbolos artísticos da cidade no que se refere a identidade cultural local? Portanto, o texto objetiva identificar a leitura dos moradores em relação ao patrimônio arquitetônico modernista e suas representações para Cataguases.

\subsection{Procedimentos Metodológicos}

Com base no objetivo supracitado, se faz necessário recorrer a métodos de pesquisa qualitativos, abordagem que visa responder questões muito particulares, em um nível de realidade dificilmente quantificável. Assim, a escolha deste método tem como justificativa a legitimação do conhecimento como uma construção coletiva, mediado por processos de reflexão e elucidação da realidade pesquisada (Minayo, 2009). A pesquisa foi dividida em: revisão bibliográfica; coleta de dados por meio de 30 (trinta) roteiros de entrevistas, aplicados durante o mês de setembro/2019 e direcionados aos cataguasenses. Os roteiros foram numerados de 1 a 30 e os entrevistados foram devidamente identificados, respeitando a ordem das entrevistas, por exemplo: 
Entrevistado 1 (E1), Entrevistado 2 (E2) e assim consecutivamente. A interpretação dos dados seguiu o procedimento metodológico de análise de conteúdo, que para Bardin (1979) apud Minayo (2009) é um

conjunto de técnicas de análises das comunicações visando obter, por procedimentos sistemáticos e objetivos de descrição do conteúdo das mensagens, indicadores (quantitativos ou não) que permitem a interferência de conhecimentos relativos às condições de produção/recepção (variáveis inferidas) destas mensagens (Bardin, 1979, p. 42 apud Minayo, 2009, p. 83).

O estudo representa o momento analisado e compreende as opiniões de 30 (trinta) participantes, não sendo generalizado a todo o contexto da cidade - isto demandaria novas pesquisas e ampliação da metodologia. Os resultados obtidos representam um recorte da realidade do município e expressam as perspectivas dos entrevistados. A partir de reflexões referentes à situação conflituosa entre os comerciantes locais e a prefeitura, o autor chegou a questionamentos relacionados à relação da população cataguasense e a valorização da história do Modernismo local. As questões levantadas propiciaram a construção do roteiro dissertativo de entrevista, buscando identificar as possíveis representações que estes bens exercem no cotidiano e na memória local. As questóes presentes no roteiro foram agrupadas em categorias principais e respectivas subcategorias, conforme o quadro abaixo.

QUADRO 1

Categorias de análise do conteúdo das entrevistas

\begin{tabular}{|l|l|}
\hline CATEGORIA & SUBCATEGORIA \\
\hline Patrimônio & $\bullet \quad$ Compreensão da história do modernismo $\bullet \quad$ Valorização e preservação do patrimônio modernista \\
\hline Pertencimento & $\begin{array}{l}\bullet \text { O modernismo como representaçăo da identidade cultural local } \bullet \quad \text { A relaçăo poder público vs. população no que tange a iniciativas de valorização da } \\
\text { história e memória local }\end{array}$ \\
\hline Turismo & $\bullet \quad$ Potencial turístico do patrimônio modernista $\bullet \quad$ Oturismo como possibilidade de melhoria na economia local \\
\hline
\end{tabular}

Elaboração própria a partir dos dados da pesquisa.

\section{O MOVimento modernista Em Cataguases - MG: BReve CONTEXTUALiZaÇÃo}

Xavier (2014) discute o Modernismo em Cataguases associando-o majoritariamente ao ideal cultural proposto por Francisco Inácio Peixoto e sua família, entre as décadas de 1920 a meados de 1960. Jovem industrial e escritor, Francisco Peixoto financiou e incentivou as principais manifestações culturais do município, posicionando a cidade como um importante polo cultural modernista brasileiro. $\mathrm{O}$ escritor foi um dos responsáveis pela formação do grupo literário "Verde" e circulação da Revista Verde - revista mensal de arte e cultura que contribuiu para a construção e afirmação do pensamento modernista na cidade. $\mathrm{O}$ Grupo Verde foi o primeiro contato dos cataguasenses com o pensamento modernista; e retomaram para o Modernismo brasileiro o entusiasmo dos primeiros anos, mas com uma consciência maior das contradições sociopolíticas do período (Sant'ana, 2006).

Além da literatura, a cidade se destaca por ter sido um importante polo experimental do cineasta Humberto Mauro e na "criação" do cinema moderno brasileiro - representada pelo "Ciclo de Cinema de Cataguases" (1920-1929) que obteve visibilidade nacional por dispor da participação de importantes nomes da cena cinematográfica brasileira. A influência da produção de Mauro ainda é presente, devido a constante produção audiovisual existente no município.

Em relação à arquitetura moderna, as obras em Cataguases apresentam elementos estéticos básicos do movimento: horizontalidade, uso de painéis pictóricos nas fachadas, pilotis de sustentação, obras em concreto armado, longas janelas horizontais de vidro, jardins planejados, brise-soleils em fachadas entre outras (Cavalcanti, 1970). Em 1941, Francisco Peixoto encomendou o projeto de sua residência a Oscar Niemeyer, com base nas características citadas anteriormente. Segundo Alonso, o projeto constitui "[...] uma residência moderna com traços da arquitetura tradicional brasileira, com jardins de Burle Marx, esculturas externas de José Pedrosa e Jan Zach, mobiliário de Joaquim Tenreiro e uma extensa coleção de obras de arte 
dispostas no seu interior" (Alonso e Castriota, 2009, p. 03). Em 1943, outro projeto foi encomendado a Niemeyer pelo mecenas cataguasense, o Colégio Cataguazes, um edifício para servir de internato masculino. (Error 1: La referencia: Alonso e Castriota, 2009, p. 03 está ligada a un elemento que ya no existe)

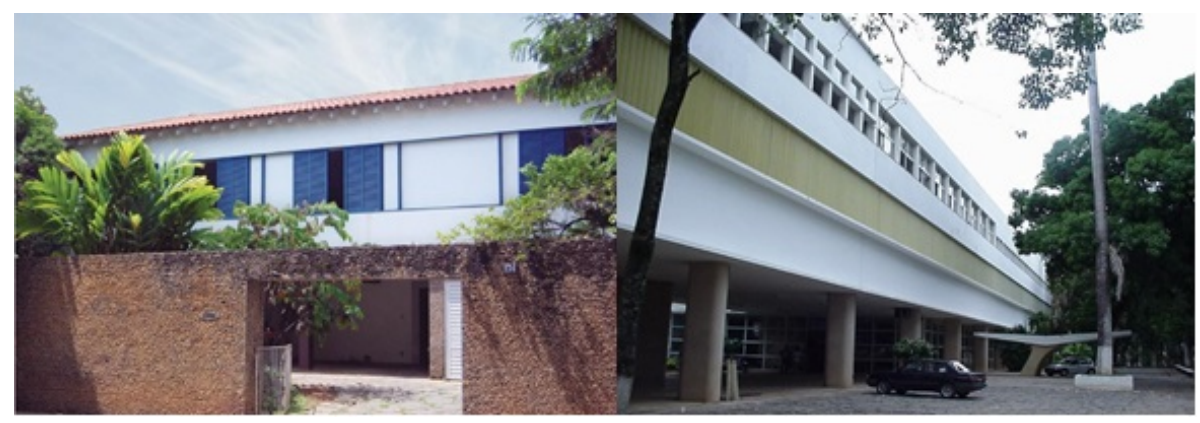

FIGURA 1

Projetos de Oscar Niemeyer: à esquerda, residência de Francisco Peixoto; à direita, Colégio Cataguases Guia da Arquitetura Modernista de Cataguases (2012, 2a ed.).

Durante a concepção do projeto do colégio, Niemeyer apresentou Candido Portinari a Francisco Peixoto, que lhe solicitou um mural de 3,15 x 18 m de comprimento para compor o saguão principal do colégio, um dos maiores desafios de Portinari. Em 1949, o edifício foi inaugurado juntamente com o mural "Tiradentes". Antes de ir para o colégio, o painel foi exposto por Portinari no Automóvel Club no Rio de Janeiro e recebeu menções graciosas por boa parte da crítica. Ao visitar a exposição, Mario Pedrosa apreciou a coragem de Portinari em buscar uma solução pictórica que atenda satisfatoriamente o que foi proposto, elogiando a ousadia de Francisco I. Peixoto “[...] oxalá a iniciativa do mecenas de Cataguazes tenha imitadores, pois dessa maneira poderemos completar o êxito mundial da arquitetura moderna no Brasil com um complemento indispensável: uma pintura mural a sua altura" (Pedrosa, 1986, p. 151).

Após a administração do Colégio ser cedida ao estado de Minas Gerais, ele não se responsabilizou pela manutenção do painel Tiradentes. Membros da elite cataguasense se uniram e custearam a manutenção do mural por um certo tempo, mas não tiveram condições de continuar arcando com despesas. Assim, a solução encontrada foi vender a obra para o estado de São Paulo (SP) que, atualmente, se encontra no Memorial da América Latina (SP).

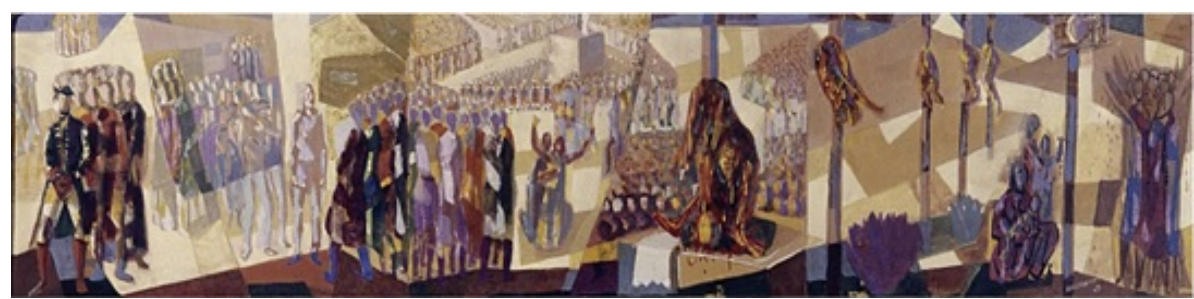

FIGURA 2

Tiradentes, 1948 - Candido Portinari.

Projeto Portinari

\subsection{O Patrimônio Arquitetônico}

Ao longo das décadas de 1950 a 1960, a elite e os dirigentes de instituições privadas encomendaram uma série de edificações de características modernas, atraídos pelos ideais construtivos e pictóricos do Modernismo e inspirados por Francisco Peixoto, totalizando vinte e nove construções entre residências, órgãos públicos/religiosos e monumentos. A elite cataguasense viu no Modernismo uma forma de demonstrar simbolicamente seu poder econômico e cultural. Arquitetos renomados como Aldary Toledo, Francisco 
Bolonha e Edgar Guimarães do Vale foram contratados para conceber projetos residenciais/institucionais, e bairros operários para proporcionar melhores condições habitacionais às famílias de operários das indústrias Peixoto. Portinari, Anísio Medeiros, Djanira, Emeric Marcier e Paulo Werneck foram os artistas responsáveis pela idealização de diversos painéis ornamentais para compor as fachadas e interiores de edifícios públicos e privados no município, sendo esse painéis majoritariamente inspirados no Expressionismo (formas humanas deformadas, uso de cores contrastantes, intensidade cromática e valorização de temas sociais) e no Cubismo (uso de formas geométricas, rejeição da noção de profundidade da dela e figuras humanas geometrizadas).

Alguns conflitos ocorreram entre a população e a elite intelectual do município, divergências evidenciadas principalmente pela demolição da Matriz de Santa Rita - de característica eclética - para dar lugar ao projeto modernista. De acordo com Miranda (1994), a população manifestou duras críticas quanto ao novo formato da igreja e pelo apego sentimental à antiga edificação. Xavier (2014) ressalta que a estratégia adotada pelo mecenas da igreja tinha como finalidade denegar construções em estilos dessemelhantes ao Modernismo, reprimindo assim a disputa no plano estético, de modo que o projeto da Matriz coincidisse e complementasse o estágio de desenvolvimento econômico baseado na industrialização - análogo ao plano modernista em nível nacional iniciado a partir da Revolução de 1930.

A utilização de murais em azulejo na fachada de propriedades privadas e de construções/monumentos públicos tornou-se uma grande forma de difusão do Modernismo. As obras foram idealizadas pela perspectiva da expressão do cotidiano regional e/ou nacional, mas que, de certo modo, não deixou de trabalhar a arte como uma forma de "denúncia social". Como pode ser percebido no painel "Fiandeiras, 1956" de Portinari (figura 3) que compõe o Monumento a José Inácio Peixoto. O artista, a partir de uma organização espacial clássica, construiu figuras femininas geometrizadas ainda decorrentes da influência cubista, caracterizando o trabalho de mulheres fiandeiras que se submetiam a rotinas exaustivas e em condições insalubres nas indústrias de tecelagem para garantir o sustento de suas famílias (Ávila, 1994).

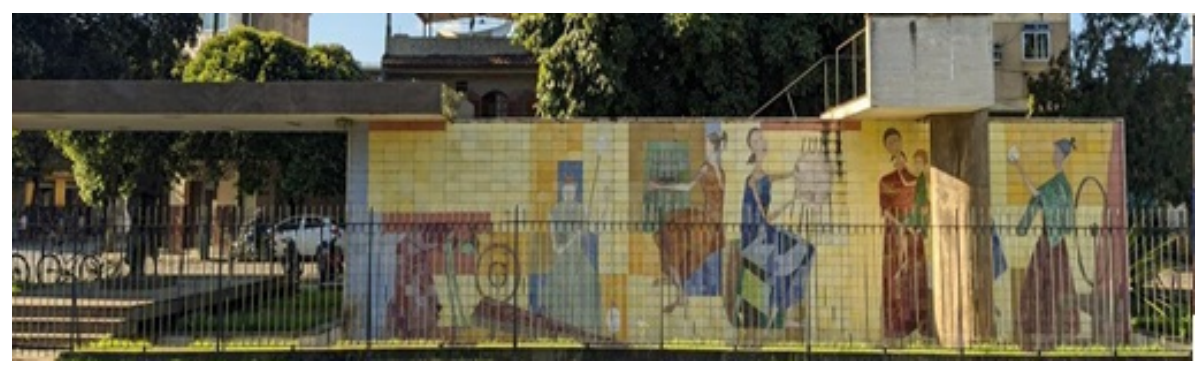

FIGURA 3

Monumento a José Inácio Peixoto, 1953-58, Francisco Bolonha.

Acervo do autor.

\section{Paisagem Cultural, Patrimônios Culturais e Turismo}

As teorias apresentadas a seguir discutem a importância de se trabalhar a interpretação do patrimônio cultural com a população local, para que posteriormente sejam pensadas (em conjunto com a comunidade) estratégias visando a valorização do patrimônio modernista de Cataguases. O conceito de "paisagem simbólica" se faz necessário para compreender a atuação dos ideais modernistas na formação da paisagem do centro de Cataguases, sendo assim Cosgrove (1983, p. 01) [1] ressalta que

Os seres humanos experienciam e transformam o mundo natural em um mundo humano através de seu engajamento direto enquanto seres pensantes com sua realidade sensorial, material. A produção e reprodução da vida material é, necessariamente, uma arte coletiva, mediada na consciência e sustentada através de códigos de comunicação. Esta última é produção simbólica. Tais códigos incluem não apenas a linguagem em seu sentido formal, mas também o gesto, o vestuário, a conduta pessoal e social, a música, pintura, e a dança, o ritual, a cerimônia e as construções. Mesmo esta lista não esgota a série de produções simbólicas através das quais mantemos o nosso mundo vivido, porque toda atividade humana é, ao mesmo tempo, material 
e simbólica, produção e comunicação. Esta apropriação simbólica do mundo produz estilos de vida (genres de vie) distintos e paisagens distintas, que são histórica e geograficamente específicos [...]

De acordo com o IPHAN, o Brasil é formado por uma vasta diversidade de paisagens, costumes e lugares. A correlação desses três aspectos apresenta uma das principais características da noção de "paisagem cultural" sendo: a ocorrência - em determinada parte do território - da coexistência entre a natureza, os espaços construídos/ocupados pelo homem, os modos de produção e as atividades socioculturais, numa relação complementar capaz de estabelecer uma identidade que não possa ser observada por qualquer um desses aspectos isoladamente (IPHAN, 2014, s/p).

A ideia de paisagem cultural nos remete a outro conceito importante: "identidade cultural". A sociologia descreve a identidade cultural "como uma modalidade de categorização da distinção nós/ele, baseada na diferença da cultura" (Cuche, 1999, p. 117). O autor analisa duas concepções a respeito da construção identitária do indivíduo: a objetiva e a subjetiva. Na primeira, a identidade pode ser interpretada como um certo tipo de "herança cultural" em que "[...] a identidade cultural remeteria necessariamente ao grupo original de vinculação do sujeito. A origem, as 'raízes' segundo a imagem comum, seriam o fundamento de toda a identidade cultural, isto é, aquilo que definiria o sujeito" (Cuche, 1999, p. 178). Já a segunda abordagem, a subjetiva, o ser identifica-se a "[...] um sentimento de vinculação ou identificação a uma coletividade imaginária em maior ou menor grau" (Cuche, 1999, p. 181). Diante disso, o autor reconhece a identidade como uma construção social, não como um dado pré-determinado. De modo que não se deve reduzir uma concepção a outra, mas sim, compreendê-las como partes integrantes de um todo.

Considerando o turismo como objeto de análise, nesse sentido, admite-se que a atividade turística deve ressaltar e valorizar os elementos que constituem uma determinada paisagem não como um mero produto, mas como um símbolo cultural que expressa e caracteriza a história e a identidade de um povo. Funari e Pelegrini (2009) atentam ao leitor para as limitações da preservação do patrimônio, visto que a comercialização dos bens é sobreposta aos interesses sociais. Os autores denotam a importância que as leis de preservação exercem na valorização do patrimônio material/imaterial e como contribuem para salvaguardar a cultura das comunidades. Para se pensar no patrimônio como um possível atrativo turístico, a interpretação do patrimônio é um elemento indispensável, sobretudo quando se tem como base culturas e paisagens tidas como especiais. "Ela possibilita aos visitantes conhecer e apreciar mais os lugares, podendo levá-los a prolongar sua permanência e estimular novas visitas" (Murta \& Albano, 2002, p. 10). Assim, a "interpretação do patrimônio" é capaz de aproximar população-patrimônio-turismo, desde que sejam estabelecidos meios inclusivos de planejamento e discussão.

\subsection{Interpretação do Patrimônio}

A interpretação do patrimônio surge como uma abordagem que denota o valor único de um determinado lugar, com o objetivo de estabelecer uma comunicação satisfatória com o visitante e na tentativa de ampliar o seu conhecimento. A principal finalidade do método é instituir uma comunicação efetiva com o visitante, valorizando os patrimônios e o desenvolvimento cultural local. A interpretação pode ser um fator decisivo para o desenvolvimento local sustentável, desde que haja a participação da população no planejamento. Logo, interpretar o patrimônio é um recurso para agregar valor a experiência do visitante, através do fornecimento de informações destacando a singularidade da história do lugar, de uma obra de arte, de um ambiente ou até mesmo de uma expressão cultural (Murta \& Goodey, 2002).

Em relação ao plano interpretativo, Murta e Goodey (2002) descrevem três etapas principais: A) inventário de registros e recursos, temas e mercados através do levantamento e sistematização dos recursos culturais/técnicos/financeiros, envolvendo os setores público-privado-civil ao considerar a história do local e o público que se deseja atrair; B) desenho e montagem da interpretação, escolha de meios e técnicas de 
interpretação apropriadas de acordo com o objeto interpretado e com o público; C) gestão e promoção: monitoramento, manutenção, avaliação permanente e treinamento da equipe que gerenciará o planejamento. Um planejamento que envolva a comunidade em seus processos decisórios “[...] contempla o potencial para a interpretação dentro de um processo compartilhado" (Goodey, 2002, p. 57).

As etapas apresentadas se incorporam neste estudo apenas para reflexões futuras, uma vez que a proposta do artigo é fomentar novas discussões sobre o tema. Deste modo, refletir sobre um plano interpretativo incorporando a diversidade existente na comunidade é estabelecer uma rede de descobertas e de apreciações para residentes e turistas. Um planejamento adequado e participativo poderá ampliar as possibilidades de desenvolvimento de projetos turísticos culturais na cidade.

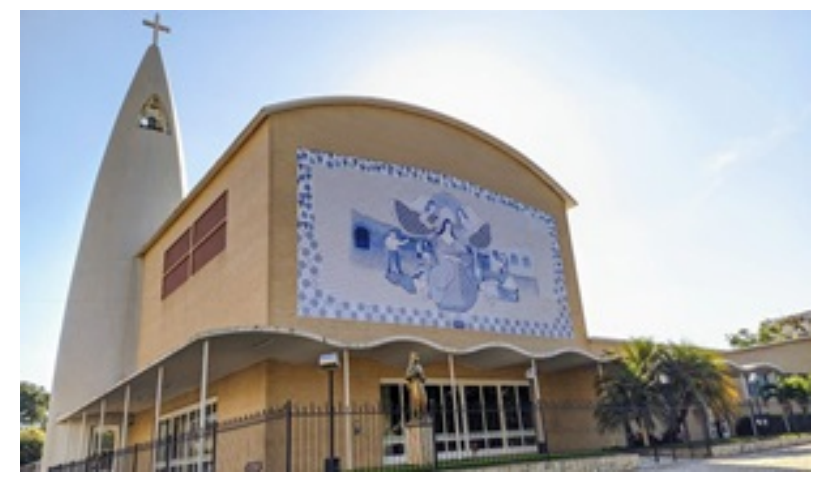

FIGURA 4

À esquerda, Matriz Santa Rita de Cássia, 1944-1968, Edgard Guimarães do Vale.

Acervo do autor

\section{Resultados e Discussões}

A partir do objeto de estudo apresentado, um roteiro de entrevista contendo sete perguntas discursivas e uma objetiva foi aplicado no mês de setembro/2019 em diferentes dias e em diversos locais do centro de Cataguases. A escolha do modelo discursivo permitiu que o entrevistado expressasse livremente sua opinião, sem se ater a respostas pré-definidas que poderiam induzir seu pensamento. As perguntas foram agrupadas em três categorias que se relacionam: a) patrimônio; b) pertencimento; c) turismo.

\section{QUADRO 2}

Perfil dos Entrevistados

\begin{tabular}{|c|c|}
\hline Classificação & Número de Entrevistados e Porcentagem \\
\hline Identificacão por identidade de gênero: & 15 homens (50\%) e 15 mulheres $(50 \%)$ \\
\hline $\begin{array}{l}\text { Classificação por faixa etária dos } \\
\text { entrevistados segundo o sistema SIDRA: }\end{array}$ & $\begin{array}{l}18 \text { a } 24 \text { anos: } 13,3 \% 25 \text { a } 49 \text { anos: } 70 \% 50 \\
\text { anost: } 16,7 \%\end{array}$ \\
\hline Escolaridade Concluída: & $\begin{array}{l}\text { Ensino Fundamental: } 13,3 \% \text { Ensino Médio: } \\
\text { 43,3\% Ensino Superior: } 30 \% \\
\text { Pós-Graduacão: } 13,3 \%\end{array}$ \\
\hline Renda Básica Mensal: & $\begin{array}{l}\text { Até } 1 \text { salário minimo: } 30 \% \text { De } 2 \text { a } 3 \text { salários } \\
\text { mínimos: } 56,7 \% \text { Acima de } 3 \text { salários } \\
\text { mínimos: } 13,3 \%\end{array}$ \\
\hline
\end{tabular}




\subsection{O patrimônio arquitetônico modernista}

A primeira categoria discute a valorização da história do Modernismo na cidade. Assim, buscou-se identificar se os entrevistados têm consciência sobre as origens desse patrimônio e principalmente se é de seu conhecimento o tombamento realizado pelo IPHAN. Essa foi a única pergunta objetiva do roteiro e com base na análise de suas respostas, $56,7 \%$ dos participantes mencionaram saber do tombamento federal realizado em 1994. Em relação a história do modernismo, 70\% dos entrevistados disseram conhecer superficialmente o assunto, como afirmam as seguintes respostas.

E4: "Não posso dizer que sei da história, mas sei partes dela, maior referência sobre o modernismo em Cataguases para mim foi da contribuição do Niemeyer, essa parte é a que mais ouvi falar, posso dizer que hoje olho uma casa "diferente" no meio de outras e sei que tem aquela pegada modernista é por conta de Cataguases. Esses painéis para mim trazem uma visão diferente da cidade, um charme, já tive o prazer de conhecer gente que vai a Cataguases atrás das construçóes e obras modernistas e ouvir essa pessoa admirada com a cidade traz uma alegria diferente, algo de se orgulhar e 'tirar onda"' (informação verbal).

E8: "Conheço sim! Representam a importância histórica de Cataguases no movimento modernista no Brasil, com destaque para obras de Niemeyer e Portinari” (informação verbal).

As afirmações evidenciam que a história do Modernismo está interligada às construções de Oscar Niemeyer e as obras de Portinari, muito mais pela consagração dos artistas do que pela relação das obras com a cidade e seu contexto histórico. O Modernismo em Cataguases está vinculado ao ideal de desenvolvimento difundido pela elite intelectual, como ressalta Xavier (2014) ao exemplificar sobre a demolição de alguns bens que não condizem com a estética modernista na cidade; assim como no governo de Getúlio Vargas, a estética modernista representava o desenvolvimento industrial e econômico do país. Os relatos e o baixo conhecimento sobre o tombamento federal do patrimônio podem denotar a escassez das discussões sobre a história local e a falta de iniciativas de preservação/valorização dos bens culturais do município. Apesar de apenas 30\% dos entrevistados responderem que não conhecem a história do Modernismo, isso pode evidenciar que as discussões acerca do tema são escassas e a população tenha se distanciado cada vez mais do assunto, seja por falta de incentivo público ou até mesmo desinteresse pessoal, pois a história local não tem sido pauta nas escolas, por exemplo.

O conhecimento sobre os significados dos painéis também foi outro problema apontado na pesquisa. Os participantes não compreendem os aspectos simbólicos das obras, ou seja, os elementos presentes nos murais dialogam com o contexto social da época em que foram produzidos. Segue como exemplo a obra "Fiandeiras, 1956" de Portinari (figura 3), ao "denunciar" a exploração e o cotidiano árduo de jovens mulheres na tecelagem, como é visto através do penteado em formato de coque em todas as personagens (evidência da preocupação com os casos em que mulheres sofriam acidentes, muitas vezes fatais, ao terem seus cabelos presos na engrenagem das máquinas). Em relação a preservação/valorização do patrimônio pela própria população, a discussão apresenta perspectivas contrastantes como menciona o E10:

E10: "Conhecido sim, valorizado não. Tínhamos um projeto de educação patrimonial da Secretaria de Cultura com as escolas. Os alunos faziam uma visita guiada por todos os pontos, mas não existe continuidade” (informação verbal).

Ao mesmo tempo em que demais participantes mencionam a falta de valorização pela própria comunidade e pelo poder público, como o E2:

E2: "Não é nem um pouco valorizado, tanto pela população quanto pelos governantes que são incapazes de explorar o potencial turístico da cidade e de conservar os patrimônios e incentivar mais cultura” (informação verbal).

Alguns moradores acreditam que as obras são valorizadas e estão bem preservadas, como o E9:

E9: "Acredito que sim, pelo fato de serem estas obras, conhecidas e preservadas por todos, não sofrendo por exemplo, atos de vandalismo. Mas, poderiam ser melhores utilizadas para fomentar o turismo na cidade, levando em consideração os artistas renomados, reconhecidos internacionalmente" (informação verbal).

Vale ressaltar que a maioria das edificações e seus respectivos painéis decorativos são de natureza particular, pertencentes a instituições privadas e/ou religiosas e residências familiares. Sendo assim, a preservação se dá 
pela utilização efetiva dos espaços - seja como moradia ou centro cultural - o que requer de seus proprietários cuidados mais atentos. A discordância entre os entrevistados evidencia percepções de gerações diferentes. Os que acreditam que não há valorização são pessoas ligadas a instituições de ensino, moradores mais antigos e que já vivenciaram projetos de valorização e resgate da memória histórica da cidade e viram a descontinuidade dos projetos por novos governos. Já os que acreditam na valorização, são moradores jovens e possuem um olhar menos crítico e mais positivista, exaltam a beleza dessas edificações, compreendem parcialmente a história e/ou estão inseridos em programas culturais locais.

De certo modo, os painéis estão bem conservados justamente por serem de natureza particular, não há relatos sobre casos de vandalismo com as obras. $\mathrm{O}$ bom estado de conservação pode indicar um certo respeito e afetividade da população com o patrimônio, mesmo sem que haja a total compreensão de sua história e de sua simbologia. No contexto de valorização dos bens culturais pela própria comunidade, o plano interpretativo surge como uma ferramenta de inclusão nas discussões referentes ao planejamento local, desde que o processo seja compartilhado e participativo. A interpretação do patrimônio poderá permitir que os moradores expressem opiniões e explicitem as percepções de valor das obras existentes na cidade. Portanto, "o processo de interpretação poderá dessa forma levar a comunidade local a descobrir a si mesma" (Goodey, 2002, p. 57).

\subsection{Relações de pertencimento}

A segunda categoria analisa as relaçóes de pertencimento, o sentimento de afetividade dos moradores com as obras modernas e a relação do poder público com a população referente à valorização da história local. Dessa forma, a questão sobre iniciativas de valorização do patrimônio reconheceu (através da fala dos entrevistados) um sentimento de afetividade com os painéis e demais obras; devido ao tom de indignação ao mencionarem a falta de valorização por parte da prefeitura e ao carinho em que os participantes propunham maneiras de sanar esses problemas. Assim, nota-se um sentimento de insatisfação com o poder público local. Os entrevistados comentaram sobre a falta de iniciativas para resgatar a memória da cidade, como isso tem propiciado para que os mais jovens não reconheçam o Modernismo como a própria história local e como os ideais modernos reestruturaram a organização sociocultural do município.

E3: “A prefeitura deveria criar um programa de valorização, com por exemplo tour disponíveis para a população, a fim de que esta valorize mais o nosso patrimônio. Ensinar nas escolas -eu tive isso- quais os patrimônios e fazer excursões com as crianças pela cidade" (informação verbal).

E18: "Incentivar as crianças nas escolas a aprenderem mais sobre a cultura modernista da cidade; ter placas de identificação que falem a respeito dos patrimônios para que visitantes tenham conhecimento das histórias; ter uma pessoa na cidade com vasto conhecimento sobre modernismo e sobre os patrimônios seja na biblioteca municipal ou no acervo da cidade, ou Câmara, de forma que visitantes tenham acesso à um guia e à informações concretas nas visitas da cidade" (informação verbal).

Funari e Pelegrini (2009) promovem a reflexão da complexidade das leis e iniciativas de preservação do patrimônio: tombamento não é sinônimo de valorização. Se um bem tombado não exerce uma função social para com o seu local (como, por exemplo de educação patrimonial), ele se distancia da comunidade e perde seu caráter memorável, pois não dialoga com os interesses da população e ao invés de criar um sentimento de pertencimento ocorre o contrário, o distanciamento. Um bem tombado deve ressaltar a história e a memória local, assim deve-se pensar a interpretação do patrimônio como um dos meios mais eficazes de valorização. No que se refere ao Modernismo como identidade cultural de Cataguases, podemos nos apoiar nos estudos de Denis Cuche (1999) de forma a compreender que:

A construção da identidade se faz no interior de contextos sociais que determinam a posição do agente e por isso mesmo orientam suas representações e suas escolhas. Além disso, a construção da identidade não é uma ilusão, pois é dotada de eficácia social, produzindo efeitos sociais reais (Cuche, 1999, p. 182). 
De acordo com a pesquisa, 43,3\% dos entrevistados acreditam que o patrimônio modernista representa a identidade cultural da cidade, devido aos ideais modernos terem marcado época ao posicionar a cidade como polo cultural relevante para o país. Além disso, as edificações denotam história e beleza, orgulho para muitos. Segundo o E28:

E28: "Na minha opinião sim, como é conhecida também como o berço do cinema nacional através de Humberto Mauro! O conjunto arquitetônico modernista nos dá uma identidade onde somos referência na redondeza para citações e visitações de alunos de arquitetura e por ser mais um aspecto importante que constitui ricamente a história da nossa cidade!" (informação verbal).

Outras respostas também denotam a produção audiovisual como um fator cultural importante da cidade, isso está ligado diretamente com a produção cinematográfica iniciada na década de 1920 com o "Ciclo de Cinema de Cataguases" liderada por Humberto Mauro. Já 56.6\% dos entrevistados não consideram o patrimônio moderno como identidade cultural devido a sua desvalorização por parte da própria população, que aos poucos vem se distanciando dessa história. Alguns participantes citaram que os jovens não são estimulados a questionar e a refletir sobre as origens do movimento na cidade. Segundo o imaginário dos moradores mais tradicionais, os símbolos, os significados e a história do Modernismo cataguasense não estão sendo passados adiante, permanece apenas em suas memórias ou naqueles que, por algum motivo aleatório, despertam interesse por artes/cultura.

E19: "Não! Porque a juventude nem sabe que existe e nem é incentivada a buscar entender o que são essas pinturas" (informação verbal).

E27: "Entendo que não, por falta de valorização, incentivo e visibilidade isso se perdeu com o passar dos anos, não ouço falar mais dos trabalhos que tinham nas escolas, nas visitas aos museus com as crianças, tá tudo se perdendo!" (informação verbal)

Esse imaginário tradicional não deve ser visto como uma afirmativa totalizante, já que a maior parte dos participantes apresentam faixa etária entre 20 e 29 anos, se interessaram pela pesquisa e denotam certo conhecimento (mesmo que superficial) sobre o movimento. A contradição identificada através dessa questão é importante para a discussão, pois possibilita a ampliação de estudos sobre a identidade cultural de Cataguases, visto não haver uma conclusão concreta referente ao tema. Os entrevistados possuem visões distintas sobre a identidade cultural da cidade e estas perspectivas sinalizam a diversidade cultural do município através de outras manifestações artísticas, para além do patrimônio arquitetônico. Para o Modernismo ser reconhecido como manifestação identitária do município é necessário identificação pessoal da comunidade com as obras, as reconhecendo como a sua própria história, isso só ocorrerá se houverem investimentos qualitativos em educação ou em demais projetos de valorização patrimonial.

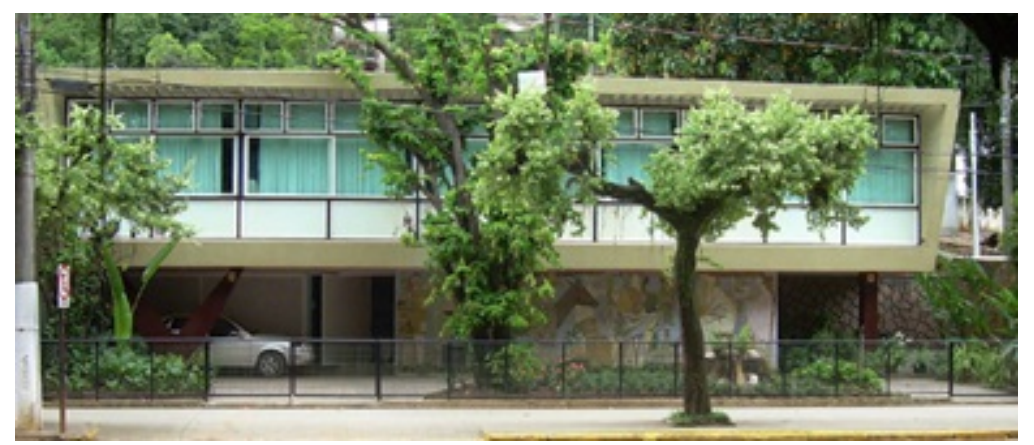

\section{FIGURA 5}

Antiga residência da artista Nanzita, 1957-58, Francisco Bolonha. Guia da Arquitetura Modernista de Cataguases (2a ed), 2012. 


\subsection{O potencial turístico}

A atividade turística foi mencionada diversas vezes ao longo das entrevistas. Os participantes propuseram reflexões sobre o potencial turístico da cidade e como o conjunto arquitetônico modernista pode se tornar um atrativo. Este fato denota a importância de se pensar o turismo como uma estratégia viável de melhoria socioeconômica e cultural no município e como os entrevistados enxergam possibilidades benéficas neste segmento. Um aspecto importante é a iniciativa de utilização da ferrovia para o transporte de passageiros. Em 2018 houve a viagem experimental do trem turístico ligando Cataguases a Três Rios (Rio de Janeiro), elemento que pode ter despertado nos residentes a vontade de incorporar o turismo como atividade profissional. Aparentemente, as notícias encontradas denotam que o projeto ainda está em processo de planejamento e finalizando os processos burocráticos cabíveis.

Dentre os 30 moradores, apenas um entrevistado se opôs ao turismo como possibilidade de desenvolvimento econômico, ao dizer: "Não, o que desenvolve uma cidade são empresas que geram empregos para população" (informação verbal) - E7. De acordo com algumas respostas, o turismo desenvolvido de forma participativa e respeitando as diversidades de percepções poderá contemplar uma grande parcela da população, melhorando a economia familiar, desde que os moradores sejam incluídos no processo de planejamento e obtenham os benefícios gerados pela atividade. Dentre 29 respostas positivas, as mais interessantes apresentam pontos que reforçam a condição do planejamento participativo e a falta (ou pouco conhecimento) das obras modernas:

E3: "O turismo de fato faria bem para as finanças da população e consequentemente ao poder público. Para ser feito de forma efetiva e melhor para todos, a própria comunidade local o devia regular, com o mínimo possível de interferência da prefeitura e autoridades representantes do poder público, assim seria garantida maior liberdade às famílias locais para lucrarem por diversos métodos, aproveitando-se do turismo para venderem as mais diversas coisas, desde bebidas, alimentos até souvenires" (informação verbal).

E6: "Sim. Faltam mais informações sobre estas obras, a maioria com pequenas placas, onde se fica difícil, muitas vezes, saber quem é o artista. A criação de uma agenda cultural, com música, teatros, exibição de filmes, oficinas, gastronomia local, alinhadas com maior identificação destas obras, com certeza fomentaria o turismo na cidade" (informação verbal).

Por meio da fala dos moradores percebe-se a vontade de investir no turismo com viés participativo e educativo, em que a arte e a cultura sejam compreendidas com o seu devido valor e não simplesmente como mera paisagem contemplativa de belos painéis e de arquitetura inusitada. Assim, conforme Murta \& Goodey (2002) interpretar o patrimônio permite denotar a singularidades das obras modernistas cataguasenses e transmitir o conhecimento para os demais e para a própria sociedade, além de ressaltar a importância histórico-cultural da cidade.

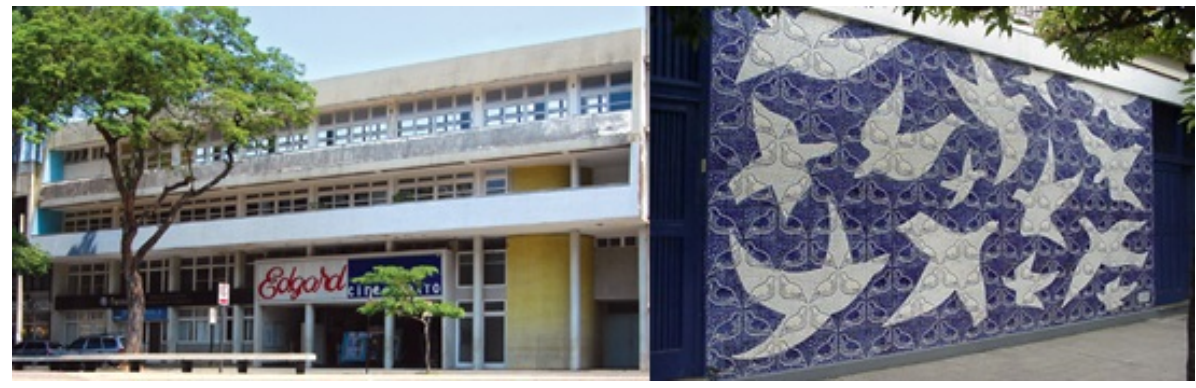

Figura 6

À esquerda: Edgard Cine Teatro, 1946-52, Aldary Toledo e Carlos Leão. À direita:

Painel "Os Pássaros”, 1956, Anísio Medeiros - fachada do Educandário D. Silvério. Guia da Arquitetura Modernista de Cataguases (2a ed), 2012 e http://www.asminasgerais.com.br/. 


\section{Considerações Finais}

Aos poucos, a história do Modernismo vem se perdendo não só por falta de investimentos, mas por não abranger grande parte da sociedade, que se vê em alguns casos fora do contexto da produção cultural atual - ressaltada por alguns como uma cultura elitizada. Através da perspectiva dos entrevistados ainda não se pode afirmar que as construções modernistas sejam a identidade cultural da cidade. Ao mesmo tempo em que alguns afirmaram o Modernismo como um forte símbolo histórico-cultural, outros apontaram a produção audiovisual como a identidade do município. Os entrevistados relataram ser necessário trabalhar melhor as iniciativas culturais, para que grande parte da população se identifique com a produção artística local. Os participantes expressaram o orgulho que sentem pela cidade abrigar tais obras, mas sentem a necessidade de projetos que valorizem o patrimônio junto à própria comunidade, para que a história não se perca nas próximas gerações. O Modernismo pode ser compreendido como parte da construção identitária dos cataguasenses, mas não como único elemento.

O estudo apresenta uma certa indignação dos entrevistados com a Prefeitura Municipal, ao mencionarem que o órgão não desenvolve iniciativas de valorização do patrimônio (perspectiva de certo modo contraditória). A prefeitura disponibilizou apoio técnico através da Secretaria de Cultura e Turismo para a criação de um dossiê para a candidatura de Cataguases como Cidade Criativa, na categoria de Audiovisual da Organização das Nações Unidas para a Educação, a Ciência e a Cultura (UNESCO). Infelizmente a cidade não foi contemplada. A contradição apontada pode evidenciar uma falha na comunicação entre a prefeitura e os moradores. Então, cabe ao poder público buscar fontes de divulgação de projetos e ações para além de mídias sociais, propiciando um contato mais direto com a população, seja através de assembleias públicas, contato com escolas, instituições e associações de bairros etc.

No seguimento turístico, Cataguases atrai um pequeno número de visitantes com viés científico. Discentes e docentes de arquitetura de diferentes localidades estudam as edificações modernistas e seus elementos construtivos, o que indica a relevância nacional das obras modernas. Além disso, o município já recebeu eventos científicos e técnico-educativos ligados ao patrimônio cultural, como o Festival Ver e Fazer Filmes e o Congresso de Arquitetura, Turismo e Sustentabilidade (CATS) em 2018. Os eventos atraíram um público intelectualizado e predisposto ao conhecimento, mas que de certo modo se distanciam da sociedade. Desta forma, os eventos científicos deveriam dispor de seus resultados à massa populacional e realizar rodas de conversa e palestras públicas para inserir a comunidade no debate, pois são meios de valorização da cultura local e de aproximação entre visitante-comunidade.

Pensar em um plano de interpretação do patrimônio com a própria comunidade é imprescindível. O método interpretativo possibilitará a inserção dos cataguasenses nos processos de planejamento e de discussão, expressando suas expectativas e anseios, permitindo que os moradores lutem pela continuidade dos projetos. Além de novas ações, programas como o roteiro interpretativo (realizados em parceria com as escolas locais) devem ser retomados e ampliados para outras regiões. Investimentos em educação patrimonial são procedimentos de valorização da memória local e, no caso de Cataguases, poderá viabilizar ao morador se sentir parte dessa história.

Por fim, os ideais construtivos modernistas foram um dos principais agentes produtores da paisagem cultural de Cataguases no século XX. As técnicas baseadas na concepção de desenvolvimento remodelaram o centro da cidade e expandiram o perímetro urbano para a margem direita do Rio Pomba - com a construção da Companhia Industrial Cataguases e dos bairros operários, ocupando regiões pouco exploradas. Se Cataguases é reconhecida nacionalmente como "galeria a céu aberto" é porque sua paisagem é de fato uma "grande obra artística e moderna”, contendo edificações e monumentos que exemplificam a "época de ouro" do município, denotando todo o poder econômico e cultural que a cidade possuiu na década de XX. 


\section{REFERÊNCIAS}

Alonso, P. H. (2012). Guia da Arquitetura Modernista de Cataguases (2 a ed.). Instituto Cidade de Cataguases.

Alonso, P. H.; Castriota, L. B. (2009) Conhecer para preservar: documentação e preservação do patrimônio modernista em Cataguases, Minas Gerais. In: $8^{\circ}$ Seminário DOCOMOMO Brasil. Cidade Moderna e Contemporânea: Sintese e Paradoxo das Artes, Rio de Janeiro.

Ávila, C. (1994). Artes Plásticas: Cataguases: a importação plástica como vontade modernista. In: S. M. Miranda, et. al. Cataguases: um olhar sobre a modernidade. Instituto Francisca de Souza Peixoto.

Cavalcanti, C. (1970). História das Artes: Curso elementar - Da Renascença fora da Itália até os nossos dias (2a ed.). Civilização Brasileira, pp. 273-292.

Cosgrove, D. E. (1983). Towards a Radical Cultural Geography of Theory. Antipode- a Radical Journal of Geography, 15 (1), pp. 01-11.

Cuche, D. (1999). A noção de cultura nas ciências sociais. Edusc.

Fabris, A. (1994). Modernidade e vanguarda: o caso brasileiro In: A. Fabris (Org.) Modernidade e modernismo no Brasil. Mercado de Letras, pp. 09-24.

Funari, P. P.; Pelegrini, S. C. A. (2009). Patrimônio Histórico e Cultural. 2.ed. Rio de Janeiro: Zahar, 73p.

Goodey, B. (2002). Interpretação e Comunidade Local. In: S. M. Murta \& C. Albano (Orgs.). Interpretaropatrimônio: um exercicio do olhar. Editora UFMG, pp. 47-58.

Instituto do Patrimônio Histórico e Artístico Nacional [IPHAN]. Patrimônio Cultural. Acesso em 21 jun 2019 . ht tp://portal.iphan.gov.br/pagina/detalhes/218

Instituto do Patrimônio Histórico e Artístico Nacional [IPHAN]. Paisagem Cultural. Acesso em 21 jun 2019. http ://portal.iphan.gov.br/pagina/detalhes/899/

Minayo, M. C. S. (2009). Pesquisa Social. Teoria, método e criatividade. (18ed.). Vozes.

Miranda, S. M. (1994). Arquitetura. In: S. M. Miranda, et. al. Cataguases: um olhar sobre a modernidade. Instituto Francisca de Souza Peixoto.

Murta, S. M. \& Albano, C. (2002). Interpretação, Preservação e Turismo: uma introdução. In: S. M. Murta \& C. Albano (Orgs.). Interpretar o patrimônio: um exercicio do olhar. Editora UFMG, pp. 9-11.

Murta, S. M. \& Goodey, B. (2002). Interpretação do Patrimônio para Visitantes: um quadro conceitual. In: S. M. Murta \& C. Albano (Orgs.). Interpretar o patrimônio: um exercício do olhar. Editora UFMG, pp. 13-46.

Pedrosa, M. (1986). O painel de Tiradentes. In: O. B. F. Arantes (Org.). Acadêmicos e modernos. EDUSP, pp. $176-177$.

Sant'Ana, R. M. (2006). O Movimento Modernista Verde, de Cataguases - MG. Em Tese - Portal de Periódicos da Faculdade de Letras - UFMG, 10, pp. 172-177.

Xavier, W. S. (2014). Mitos fundadores, tradições inventadas e sentidos de cidade: uma incursão pela velha e nova Cataguases-MG. RAM, Rev. Adm. Mackenzie, 15(6), pp. 122-148.

Zilio, C. (1994). A questão política no modernismo. In: FABRIS, A. (Org.) Modernidade e modernismo no Brasil. Campinas: Mercado de Letras, pp. 111-118.

\section{Notas}

[1] Traduzido por Olívia B. Lima da Silva em Cosgrove (1983). 